\title{
Implementation and evaluation of an educational programme to support registered nurses during clinical supervision of student nurses in medical and surgical wards in a training health facility, Namibia
}

\author{
Hanna Neshuku *, Amukugo Hans Justus \\ Lecturers, School of nursing, Faculty of health Sciences University of Namibia \\ *Corresponding authorE-mail: hneshuku@unam.na
}

\begin{abstract}
The purpose of this paper is to provide an account of the implementation and evaluation of the educational programme was to support registered nurses in the Oshana region, Namibia educationally, in order to enable them to provide effective clinical supervision of student nurses The researcher selected to conduct a workshop because during a workshop it is possible to have two-way communication that encouraged the exchange of ideas and facts with the aim of sharing valued information among one another. The duration of the workshop was two days. The workshop was attended by registered nurses (registered nurses from a training institution and training health facilities) from the Oshana Region. Participants were selected using a criterion sampling method (registered nurses who were supervising second and third year nursing students during clinical practice; those registered nurses were from medical and surgical wards at training heath facilities in the Oshana Region and had been working there for a year or more). There were no limitations on the number / sample size; the researcher allowed all participants who turned up to attend the workshop resulted in seventeen participants attended the workshop. The programme was implemented in three phases which in turn was divided into sessions. The orientation phase provided an introduction to the workshop where aspects related to the purpose, goals, and objectives of the workshop and logistical arrangements of the implementation of the programme were discussed. The working phase consisted of three sessions which is corresponding to the programme objectives. The implementation of each session was based on the specific objective activities of that session and it was expected to produce an outcome that would help the registered nurses during the execution of their clinical supervisory duties of nursing students During the termination phase two qualitative evaluations were done firstly, the evaluation of the programme implementation for participants to describe their experiences from the programme activities. Secondary, post implementation evaluation or impact evaluation was done, two months after the implementation of the programme with the aim of assessing the long-term effects of the programme activities as might be signified by changes in the way of clinical supervision of student nurses was provided after the programme implementation.

The results of the programme implementation evaluation indicated a strong feasibility for implementation as could be inferred from the successful implementation of the programme activities as planned and by the programme contentment with the context of implementation. The post evaluation outcome evaluation indicated that the participant find the programme worthwhile and demonstrated a positive attitudes towards the programme as they were satisfied with the programme tried to implement the knowledge gained during their routine activities and recommended the decentralization of the programme.
\end{abstract}

Keywords: Implementation; Evaluation; Educational Programme; Support; Clinical Supervision.

\section{Introduction}

Clinical practice has been an integral part of nursing education. Sharif and Masouri (2005) hold the opinion that it prepares student nurses to be able to master the art of "doing" as well as "knowing" the clinical principles in practice. It further stimulates students to use their critical thinking skills for problem solving. Both education and service institutions share in the creation of a supportive learning milieu through clinical supervision of student nurse. To master the discipline of nursing and the increasingly complex skills required to deliver safe and effective patient care, both theoretical and clinical practice are essential for nursing students (American Association of Colleges of Nursing, 2011).

A qualitative, exploratory descriptive and contextual study that describe the experiences of registered nurses and student nurses regarding the clinical supervision of student nurses in medical and surgical wards was conducted. The data from a that study describe the experiences of registered nurses and student nurses regarding the clinical supervision of student nurses in medical and surgical wards highlighted the unmet need of student nurses and registered nurses during clinical supervision. (Neshuku, 2015) As a result an educational programme was developed for implementation to cater for challenges identified during clinical supervision in order to support registered nurses during clinical supervision of student nurses. 


\section{Implementation of the educational pro- gramme}

\subsection{Purpose of the study}

The purpose of this paper is twofold. Firstly to discuss the implementation of educational programme interventions to registered nurses entitled to supervise student nurses during clinical practice in medical and surgical wards of training hospitals in Oshana region Namibia. Secondary it highlight the evaluation of the programme implementation with the aim of validating successfulness of the implementation of the programme developed as well as long-term effects as outcome of the programme intervention on the part of the recipients.

\subsection{Study design and method}

A qualitative descriptive study was conducted to implement the educational programme intervention and to carry out the evaluation of the programme implementation. For the implementation of an educational programme to support registered nurses during their clinical supervision, the researcher selected to conduct a two days' workshop with the reason that during the workshop it is possible to have a two way communication whereby ideas and facts are exchanged with the aim to get valued information from both sides. The programme was implemented in three phases. Programme implementation evaluation was done every day the researcher also conducted focus group discussions with registered nurses and student nurses in the medical and surgical wards, two months after the implementation of the programme to assess the long-term effects of the programme activities as might be signified by changes in the way of clinical supervision of student nurses

\subsection{Objectives}

The objectives of the programme were to:

- Address the managerial challenges and educational challenges identified as affecting the clinical supervision of student nurses in order to support registered nurses during the clinical supervision of student nurses

- Address educational challenges identified as affecting the clinical supervision of student nurses in order to support registered nurses during the clinical supervision of student nurses

- Create a conducive environment for and enhance constructive interpersonal relationships among registered nurses and between registered nurses and student nurses that promote effective clinical supervision.

\subsection{Methods for implementing}

The programme was implemented in three phases as follows: Orientation phase: This phase provided an introduction to the workshop where aspects related to the purpose, goals, and objectives of the workshop and logistical arrangements of the implementation of the programme were discussed. It was held in the morning on the first day of the workshop. Participants were informed about the purpose of the programme and asked to consent to participating in the development of the programme. The ground rules and expectations were discussed and repeated at the beginning of each session. The general aims and objectives of the workshop were explained to the participants during the introduction. That was done in order to help participants to understand why they had been invited and to emphasise the importance of the workshop. The programme protocol and expectations were also dealt with.

The facilitator used ice breaker activities at the beginning of each session when it was needed in order to afford participants the opportunity to settle down and get comfortable with one another, as well as to lead them into the next session. The researcher serves as a facilitator of the workshop.

Working phase: The working phase was centred on supporting registered nurses educationally in order for them to competently execute clinical supervision to nursing students. The implementation approach acknowledged the Kolb's experiential learning cycle within the paradigm of adult learning. The programme addressed the needs identified during the data analysis of the study to explore and identified the experiences of student nurses and registered nurses during clinical supervision of student nurses in medical and surgical wards in training health facility in Oshana region.. The phase consisted of three sessions corresponding to the programme objectives as follows.

Section1: Addressing managerial challenges identified as affecting negatively the clinical supervision of nursing students in order to support registered nurses during the clinical supervision of nursing students

This session aimed at addressing specifically managerial challenges experienced by registered nurses and nursing students. The researcher shared information gained from data analysis with the registered nurses in a lecture form, followed by group activities that explore how to deal with those challenges.

Managerial challenges that had been identified included too heavy a workload, the shortage of staff, and a lopsided supervisorstudent ratio, the absence of clinical instructors during clinical practice and a shortage of materials. The facilitator shared those challenges with the participants during a PowerPoint presentation. Another activity was a case scenario that was role played by the participants about the challenges identified. Group work and group discussions were planned to be conducted after the case scenario, then feedback from the groups and discussions from the groups about the strategies that they suggest for assisting registered nurses to overcome the challenges were identified. The following scenarios listed below were prepared to for this objective as follows:

Scenario 1: How to overcome the following managerial challenges during clinical supervision: Shortage of staff and too heavy a workload

Participants had to review the scenario below and answer the question provided.

You are a lecturer at a training institution. During your supervisory visit, you find a supervisor in charge of a surgical ward faced by the following situation: It is a busy day because nine patients need to undergo operations in that ward and she / he needs to conduct a supervisory session with nursing students allocated to her / his ward.

Write down your list of suggestions how she / he should mitigate this situation she / he finds him / herself in.

Scenario 2: How to deal with the shortage of materials

Mr. Andreas aged 35 years is admitted to your ward after a motor vehicle accident. Observations at the casualty revealed the following:

BP 80/60, Pulse 100/min, Respiration 30/min.

Scenario 3: Shortage of equipment

As a lecturer, during your student supervision in medical and surgical wards, you are experiencing situations where nurses are complaining about the shortage of equipment needed for nursing care and the teaching of nursing students. Write down your answers to how best this problem could be solved.

Secondly, the facilitator provides the participants with a PowerPoint presentation that was followed by a group discussion and questions, as well as comments about the issues presented. The following topics were covered to serve as support to registered nurses during clinical supervision:

You are faced with the challenge of shortage of equipment including baumanometers in your ward. View the scenario above and provide your opinions based on your supervisory role to address this challenge.

Based on the PowerPoint presentation and feedback from the group discussion the following strategies were identified and rec- 
ommended to support registered nurses during clinical supervision of student nurses

- Time management: According to Booyens (2005), time management means the effective and efficient use of time. Registered nurses were encouraged during the presentation to plan and schedule their work time to ensure that enough time was available for schedule work, as well as for expected emergency and crises that might occur.

- Planning for supervision: Planning should be done timely to allow preparation by both the supervisor and supervisee with the purpose of being able to take part in clinical supervision sessions. Supervisors should draw up a list of goals and priorities that serves as a guideline for supervision and schedules the accomplishment of these goals. Booyens (2005) lists the roles and responsibilities for both supervisor and supervisee during supervisory sessions that needs to be communicated at the beginning of the supervisory session.

- Task allocation / delegation, staff-student ratio: Participants were made aware of how to allocate / delegate tasks, for example careful planning is needed in order to decide which duties to delegate and to whom. Staff members' empowerment and motivation to perform the duty allocated to them effectively and satisfactorily need to be maintained (Booyens, 2005). Supervisors remain responsible for the delegation of tasks / duties to other staff members under their supervision and they are accountable for the way in which delegated duties are performed. Conduct meetings with health services / hospital management teams, as well as training institution staff about the number of nursing students to be allocated to the ward / unit in order to avoid overcrowding, since overcrowding is not conducive for supervision and learning in clinical practice. Conduct meetings between registered nurses at training institutions and ward supervisors to discuss student placement, objectives, supervision, and assessment (Royal College of Nursing (n.d)).

- Mobilisation of material resources needed to provide clinical supervision: Resources mobilisation to ensure that resources needed for clinical supervision are sufficient both in quantity and quality needs to be done timely and correctly. These can be made possible through: Regular consultations between registered nurses from training institutions / tutors and registered nurses in the wards to discuss how to share the responsibility of supervision of nursing students during practice. Raise concerns to the management about preceptors, mentors, clinical instructors, or other experts in nursing and peers to be involved in the clinical supervision of nursing students in the absence of their tutors or ward supervisors (Royal College of Nursing, n.d.). Discussing the strategies to be followed in order to make necessary material resources available to ensure the smooth running of supervisory processes (Hinchliff, 2005). The following theories were applied during the first session of the educational programme implementation.

Kolb's learning theory (Concrete experience: Reflection and active experimentation): Based on the challenges encountered by registered nurses during clinical supervision, participants also agreed that they were confronted by the same challenges during clinical supervision. Furthermore, after viewing the role play, participants discussed their feelings about being a good supervisor and they reflected on their own supervisory styles, making use of the information to understand their feelings and experiences (abstract conceptualisation). The active implementation was facilitated when some participants took part in the role play and shared their experiences and feelings with the other participants.

Application of learning theory: Concrete experience: By using PowerPoint presentations, participants were expected to familiarise themselves with challenges identified during the individual interviews of registered nurses and nursing students in respect of clinical supervision. It was acknowledged that participants also had experienced some of those challenges, therefore, during group discussions they were expected to comment and to discuss how they could minimise those challenges.

Active experimentation: All participants were expected to actively take part in group discussions and during role playing some participants were role players while the other group members were the audience who had to comment on the role play

Session 2: Providing registered nurses with knowledge and skills in respect of clinical supervision of nursing students

The aim of session one was to equip registered nurses with knowledge and skills about what clinical supervision is all about. This was done to address the following educational challenges as they were identified during situational analysis which were: lack of knowledge about the concept of clinical supervision and the supervisory role, supervisors with outdated knowledge and skills, gap between theory and practice as experienced by both registered nurses and nursing students during clinical supervision. To realise the abovementioned objectives, the programme implementation contained PowerPoint presentations, scenarios, role playing and group discussions about all the aspects of clinical supervision, information about the qualities and characteristics of a good clinical supervisor, as well as how to facilitate adequate preparation and continual support for registered nurses during clinical supervision.

Role and responsibilities of a clinical supervisor, as well as the core content of supervision sessions were part of information shared during the PowerPoint presentation.

Participants had to reflect while observing role playing and case scenarios, thereafter they discussed their feelings related to the role playing and scenarios with regard to their understanding of clinical supervision, their implementation of clinical supervision in the past, their preferred approach in future.

Participants also had to gain knowledge from the presentation, including knowledge about clinical supervision the characteristics of a good supervisor. All the above-mentioned information facilitated concrete experience of the participants about issues related to clinical supervision. Participants were grouped and requested to search the literature for different definitions of the concept "clinical supervision". Different definitions were prepared and shared by the facilitator. The definitions were explored and discussed with the purpose of illustrating to the participants that clinical supervision centred around the "what and how" of clinical supervision (Van Ooijen, 2000).

During that session, the facilitator presented a lecture using a PowerPoint presentation and the content of the PowerPoint presentation included the following information that was compared with the information gained through the literature search conducted by the participants, as well as information and activities that were covered during the implementation to address the educational challenges identified:

The concept "clinical supervision" is defined differently by several authors. Some focus on the aspect of "how" clinical supervision is done while other authors focus on the "what" of clinical supervision. Van Ooijen (2000) defines it as a reflective relationship that supports and improves practice. Bezuidenhout (2003) refers to clinical supervision as a professional entering into a relationship with the practical situation and having confidence to enter into an equal partnership with other health care professionals in their quest for making a real contribution to health and health care. Another definition by Consedine (2004) views clinical supervision as a term that describes a formal process of professional support and learning that enables students to develop knowledge and competencies and assume responsibility for their own practice. It is an intervention that is provided by senior members of a profession to junior members of the same profession with the purpose of enhancing the professional function of the junior members. According to Driscoll $(2000$, p. 8$)$, it is an opportunity (time) designed for interaction between practitioners.

Based on the definitions above, it is clear that clinical supervision is a formal process that is designed for the interaction between practitioners and involves support and learning, assuming responsibilities for practice, enabling practitioners and students to share 
and learn from experiences, sustain the development of professional skills, and reflective practice.

- Modes and models of clinical supervision: Another lecture presentation was done by the facilitator to provide registered nurses with knowledge and skills about the mode and models they could use during clinical supervision. The information below was shared with the participants: Modes of clinical supervision refer to the practical way of the operationalization of the process of clinical supervision while the model of supervision refers to the theoretical and philosophical underpinnings of supervision and the way in which this informs work (Freeman, 2005/6).

- Components of clinical supervision in nursing: Participants were given a lecture that enabled them to gain knowledge and skills about what was needed during the planning of a supervisory session. Hand-outs that were provided to the participants included the following information as components of clinical supervision. These information include Infrastructure; administrative foundation that allows work based learning; relevant experience in relation to clinical supervision and lastly learning culture; as well as the value of adhering to the knowledge and skills during clinical supervision

- Qualities and characteristics of a good clinical supervisor: Two role playing events were used to introduce this topic; one dealt with the qualities of a good supervisor and the other one illustrated an example of a bad supervisor. After viewing the role plays, participants were asked to brainstorm about what they thought and felt were the qualities and characteristics of a good clinical supervisor, and reflect on how they could adapt their actions when supervising nursing students, and then give feedback. The activity was guided by the instructions in the format of the following scenarios:

Scenario 4: Skills to be conveyed to students during supervision As a supervisor in a medical or surgical ward list specific skills and practice sessions that you should schedule for your student training in your wards.

Scenario 5: Registered nurse Amanda Siwayu is a newly appointed registered nurse in a medical and surgical ward where nursing students are also allocated under her supervision.

Write down your views about what she needs to be prepared for executing her role and responsibilities competently.

Several factors were provided during feedback, which were compared to the ones that were prepared by the facilitator. Nearly most of the qualities and characteristics prepared by the facilitators were mentioned and participants were encouraged to use them while they are supervising students when they would prefer to be regarded as good clinical supervisors. Hand-outs containing information about the qualities and characteristics of a good supervisor were given to the participants for further referral; the handouts included the following information:

A good supervisor needs to be knowledgeable in his / her theoretical orientation about the concept of clinical supervision and the supervisor roles, supervisee's role, supervision models, as well as clinically competent and credible. Such a supervisor is ready to share expertise by providing the supervisee with information / knowledge skills and suggestions relevant to practical problems. A supervisor needs extensive training and wide experience in the theoretical and practical field, which would assist them with achieving a broad perspective of the work. A supervisor can effectively employ a variety of supervisory interventions, and deliberately choose from these interventions based on their assessment of a supervisee's learning needs, learning style, and personal characteristics. A supervisor seeks continual growth in counselling and supervision through educational activities, self-evaluation, and feedback from supervisees, clients, other supervisors, and colleagues.

In a nursing context, skills include clinical and teaching (adult learning) skills, assessment knowledge and experience by displaying technical competencies while assisting supervisees with their work, as well as competencies in interpersonal human relations. Good supervisors also have the professional skills of good teachers (e.g. applying learning theories, developing sequential shortterm goals, evaluating interventions, and supervisee learning) and they are good consultants (e.g. objectively assessing problem situations, providing alternative interventions and / or conceptualisations of problems or clients, facilitating supervisee brainstorming of alternatives, and collaboratively developing strategies for supervisee and client growth).

They need to be objective clinicians who are open minded, nonjudgmental, non-abusive, non-threatening, a good listener, gentle, accepting, challenging, stimulating, provocative, reassuring, encouraging, possess a good sense of humour, a good sense of timing, innovative, genuine, self-aware, self-confident, and assertive. These abilities promote the establishment of sound relationships with supervisees and psychological safety.

Supervisors should be physically available and psychologically approachable, accessible, flexible, empathetic, and have a sense of humour. These attributes would assist the supervisor and supervisee with collaboratively mitigating difficult circumstances in their work and achieving a healthy perspective on their work.

Supervisors act as role models, share nursing knowledge and ethical codes, and focus on patient-related situations (Berggren \& Severinsson, 2003).

Practical scenarios about conducting supervision were presented; thereafter, participants were given group activities to write down what they knew about the roles and responsibilities of a clinical supervisor and how to handle the situations indicated in the scenarios. Group feedback was done, including a discussion of the information presented during group feedback. Thereafter, they were encouraged to utilise the knowledge and skills learnt from the discussion. Again, prepared hand-outs with the information below were provided to the participants additional to the group work information. Clinical supervisors have the following role to play during clinical supervision:

Administrative role: This role needs the following factors to be considered for the smooth running of the supervision session: time, place, and frequency of the supervision sessions.

Supportive and facilitative role: The supervisor should be able to recognise and manage problems / stress of the supervisee and develop personal awareness related to the supportive and facilitative role.

Educational role: A supervisor identifies areas of further skills and knowledge development, which in turn improves their educational role. He or she raises awareness about different models, methods, theories, and practices that could be used during clinical supervision.

Consultative role: The supervisor has to exchange and share ideas for new practice. He or she shares problems encountered during their consultative function and identifies potential solutions to those problems (Royal College of Nursing, n.d.).

Core content of supervision sessions: The researcher distributed the prepared template to the participants for discussion and comments, as well as its future utilisation during clinical supervision. The core content of the supervision session guided the registered nurse how to conduct clinical sessions; the example of the format is illustrated in Table 1.

Table 1: Core Content of Supervision Sessions

\begin{tabular}{ll}
\hline Content & Description \\
\hline Issues & $\begin{array}{l}\text { Legal and ethical issues related to the supervision that } \\
\text { need to be taken into consideration during effective } \\
\text { supervision. }\end{array}$ \\
Noals & $\begin{array}{l}\text { Negotiate goals with the supervisee that he / she could } \\
\text { use to develop a supervision plan for supervision: } \\
\text { "SMART" (Specific, measurable, achievable, realistic, } \\
\text { and timely). }\end{array}$ \\
\hline
\end{tabular}

Adopted from (www.nceta.flinders.edu.au/workforce/publicationand-resources) 
Supervisor preparation: Appropriate preparation is one of the factors that determine the success of continual student supervision and positive outcomes. Nurses who are prepared for the role are more able to facilitate the transfer of nursing knowledge and behaviour in an effective way during expert guidance and assistance. Preparatory courses are provided at some nursing schools for registered nurses who are going to be responsible for supervising nursing students (Kaviani \& Stillwell, 2000). However, the health providers are responsible to make preparatory courses available, enabling access and time to registered nurses to participate in those courses. The researcher introduced this topic in the format of case scenarios that required the participants to brainstorm their feelings about the preparation for implementing their roles and responsibilities (including clinical supervision) competently. Secondary participants were engaged in the exercise to explore the information with regard to what they think could be done to prepare the registered nurses for their supervisory role. The following are the results from the discussions:

The training of supervisors needs to include, among others, initial training, seminars, and workshops that would guide them in understanding the concepts of clinical supervision, assessment, counselling, interpersonal skills, helpful behaviour, direct guidance on clinical work, linking theory and practice, engaging in joint problem solving, and role modelling. In-service training is necessary for updating registered nurses about new developments in the field of clinical supervision when the need arises.

There must be adequate preparation and continual support for registered nurses to participate in the crucial role of student supervision through workshops and provision of educational materials, e.g. leaflets and supervision strategies. Ensure that new supervisors are orientated to the supervisory role, organisation, and policies of the facility where they are going to execute their duties (Jooste, 2009).

Ward supervisors should be role models for nursing students in whatever they do or say in the clinical setting. Therefore, it is important for them to further their academic and professional qualifications to enable them to supervise students at a required set of quality standards (Hinchliff, 2005).

According to Kilminister, Cottrell, Grant and Jolly (2007); effective supervisors possess the following qualities: Good interpersonal skills, good teaching skills, clinical competencies, and appropriate knowledge.

An equally important factor when preparing for the supervisory role, is taking into consideration that competencies and experience are essential when identifying registered nurses to supervise nursing students. Another factor is the approach and willingness to assume a supervisory role (Ohrling \& Hallberg, 2001). The education and training of registered nurses about the provision of clinical supervision should include:

Educational: Institutions in collaboration with supervisors are responsible for working collaboratively with the clinical supervisors with the purpose of supporting them with regular contact to ensure that communication systems are in place to deal with issues or queries. Communicate any changes in student programmes or assessments timely and implement an effective evaluation system. Applications of theories were applied as follows:

Adult learning approach: Participants were given a lecture that enabled them to gain knowledge and skills about providing clinical supervision to nursing students. However, they were given the opportunity to self-direct the activity and take responsibility for their decisions based on the information they had gained.

On the other hand, the researcher regarded registered nurses as adult learners with knowledge and skills and they needed to share that knowledge with the purpose of contributing to the topic presented to the other participants. Throughout the session, the participants shared their individual experiences with respect and understanding.

The facilitator accepted that all participants had some experience in clinical supervision; therefore, throughout the implementation the facilitator encouraged the participants to actively contribute during group and plenary discussions of the topic presented, as well as on the role playing and case scenarios.

Application of Kolb's learning theory: Concrete experience: Participants learnt about and acquainted themselves with knowledge and skills gained from the presentation and during group discussions; they asked questions about the topics that were presented and they discussed how they felt about the information provided.

The facilitator anticipated that participants were going to gain new knowledge and values during group discussions and selfexplorations based on PowerPoint presentations, therefore, the facilitator encouraged the participants to listen attentively during the presentations. On the basis of concrete experiences the participants learnt about or acquainted themselves with new knowledge and values from interaction with the facilitator and as a result of self-exploration, discovery of existing potential, and identification of options.

Kolb's learning theory: Active experimentation: All participants were expected to actively take part in group discussions and during the role play; some participants acted as role players while the remaining participants were the audience that had to comment on the role playing. The researcher ensured the cooperation of all participants by expecting them to alternate between being role player and members of the audience during role playing of scenarios. Active experimentation encouraged the participants to practically test concrete learning.

Objective 3: To create a conducive environment and enhance constructive interpersonal relationships among registered nurses and between registered nurses and nursing students that promote effective clinical supervision

An effective environment for clinical supervision and clinical learning includes the physical environment for delivering quality care and facilitating the development of competencies. It should provide teaching and learning opportunities, resources, and space; as well as referral materials that enhance teaching and learning. An effective environment for clinical supervision is characterised by a humanistic approach to students (Quinn, 2001).

Sound leadership values the education of nursing students and provides direction for registered nurses by promoting an environment that promotes mutual trust, respect, and support for colleagues and nursing students (Mamchur \& Myrich, 2003). The achievement of the abovementioned objective relies on emotional support that promotes constructive interpersonal relationships and good communication skills among registered nurses and between registered nurses and nursing students by providing continual guidance to supervisors in the form of coaching and career counselling sessions (Jooste, 2009). Good team work and good communication are other equally important factors that need to be established among clinical staff and staff from a training school with the purpose of promoting the sharing of feelings, ideas, and new information related to the supervision of nursing students (Fraser et al., 2006). Another strategy borrowed from Toloczko (1989) examines the implementation of stress inoculation training and social support training. The training proposed for the acquisition of sufficient knowledge, self-understanding, and coping skills to equip the nurses working at a hospital with better ways of handling stressful events. Social support training and stress inoculation training significantly improve the leadership and nurses' teamwork. According to the Royal College of Nursing (n.d. p15), some form of psychological support needs to be provided to the registered nurses who supervise students with the aim of promoting behaviour, as well as the physical and mental health that would enable them to supervise nursing students effectively. Furthermore, such support would assists registered nurses with not internalising emotions that lead to maladaptive behaviour (Fraser et al., 2006).

The aim of Session 3 was to equip registered nurses with good communication skills and to motivate them to develop good and correct interpersonal relationships with the aim of facilitating effective clinical supervision. It provided registered nurses with the information that would support open communication between them and their students. 
In order to explore constructive communication skills, the facilitator introduced a role playing activity. The participants were asked to observe a role play performed by the facilitator and one of the participants in the group. At the end of the activity, the facilitator demonstrated poor communication. The facilitator pretended to be a supervisor, while the participant pretended to be a nursing student. After the role play, the participants were asked to comment about what they had observed. Following the discussion, two participants were invited to perform the role play; this time they demonstrated constructive communication skills. Another activity in this regard was done in the form of a scenario about the ways in which to communicate messages in order to make sure that it is clear, understood, and reached the student timely. The participants provided information based on the scenario about the effective communication of messages to students while commenting and emphasising the constructive communication skills observed.

Scenario 7: Means of communication

Mrs Brown is a supervisor of a male ward. She intends to carry out an orientation sessions with nursing students allocated to her ward.

Write down your views that would assist her to ensure each student receives the invitation to the session.

Application of Kolb's learning theory

Concrete experience, abstract conceptualisation, and active experimentation: Participants gained new knowledge and skills with regard to communication and interpersonal relationships by means of direct observation of the role play and participation. They analysed their observations to make sense of and add value to clinical supervision. Secondly, they reflected on their ways of communication and their interpersonal relationships.

Kolb's learning theory: Concrete experience: Participants gained knowledge and information from the presentation and analysed it by discussing it in related to their own experiences.
Application of Kolb's learning theory: Abstract conceptualisation:Another activity that supervisors and supervisees engaged in during the programme implementation was the abstract conceptualisation of the practising emotional support counselling and active experimentation of participants during role playing and group discussions while reflecting on their of interpersonal relationships and ways of communication. Abstract conceptualisation enabled the participants to systematically comprehend what would be learnt and to apply newly acquired knowledge and skills in terms of interpersonal relationships and communication.

Application of Kolb's learning theory: Active experimentation:Participants were involved in role playing and group discussions while reflecting on their interpersonal relationships and ways of communication.

Termination phase: During the termination phase, all the issues related to registered nurses' experiences during the implementation of the programme were summarised and reflected upon.

\section{Programme implementation evaluation}

Programme implementation evaluation was conducted after the programme implementation just after the

Implementation of sessions, to assess the feasibility of the programme implementation. For this purpose evaluation, data was collected by the means of filling in the evaluation tool which was compiled by the facilitator and distributed to the participants to write on their individual responses. Open ended questions were used in order to allow participants to express themselves without limitations.

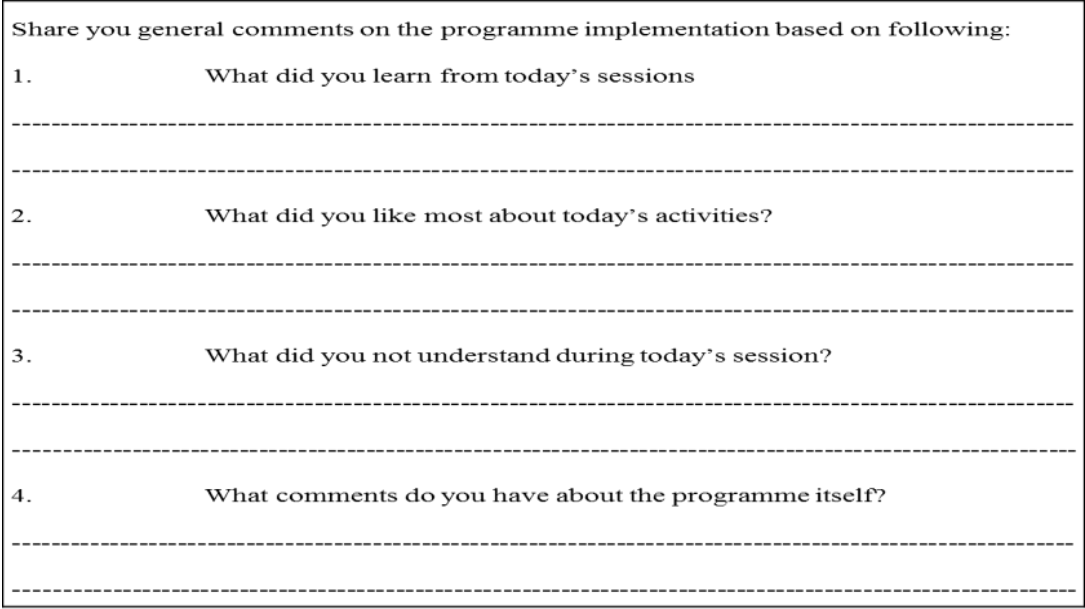

Fig. 1: Programme Implementation Evaluation Tool

Participants were requested to give their comments about the day's presentation.

The information derived from answering this question is likely to justify the quantity of learning from the programme by the participants. The participants described the programme as essential and the activities of which can enable them to provide effective clinical supervision top student nurses. They responded to the first question as it appeared on the assessment form, as follows:

1) "What did you learn from the sessions which were presented today?"

"I have learned the definition of clinical supervision and that clinical supervision is a formal process of the profession and needs to be planned." I learnt what good communication skill is between each level of student education" "What verbal and non-verbal communication is and the advantages of clinical supervision of student nurses and how to bring in changes which facilitate team work in the workplace".
"The information about qualities of a good supervisor adds to my knowledge on how the supervisor should be".

"I learnt how to supervise student nurses in the clinical area."

"I learned that clinical supervision should be formal and continuous. I also learnt about the models of clinical supervision and how to use them in practice. I also learned about my role and responsibilities as a clinical supervisor."

"I learned an important thing today on how to narrow the gap between theory and practice."

"I learned the principles of clinical supervision as a guide for me when I will be involved in the clinical supervision of student nurses."

"I learned how to maintain a good relationship between myself, my colleagues and my students."

"I learned how to communicate openly; I think I learned many good things in this workshop".

2) "What did you like most about today's activities? 
By answering this question the participants are expected to provide their view on which implementation activities help them most to learn.

Participants responded as follows:

"I have enjoyed the role play most, it was educational, and especially that it demonstrated real life situations".

"We had fun moments; I can realize that most registered nurses do not supervise student nurses in the correct way."

"I ended up criticizing myself, especially after the last scenario on communication presentation which states as follow: They may forget what you say but they will never forget how you made them feel. It made me to feel the reality".

"I liked the introduction to session one where participants were asked to answer the following questions: "Tell me about the best registered nurse you have ever had and what made him or her special? It was really a fun moment of sharing."

"Today's activity was about reality and I learnt that we don't try out different models of clinical supervision."

"I liked the part that states that supervisors are the advocacy agents for students and that we are the ones who should teach students and show them what is right and what is not right."

"I liked the portion on how to deal with challenges; it contributed to my knowledge on how to go about it."

3) "What did you not understand during the sessions for today?"

The information derived from answering the abovementioned question may serve as identified stumbling block to quality learning by the participants during the implementation of to programme and programme activities.

Participants responded as follows:

"None, I understood almost everything."

"Everything was just important and great to me."

4) "What did you understand during today's sessions?" were: "I understand about good clinical supervisors and their responsibilities."

"Possible clinical supervision scenarios used during clinical supervision of students and to be a role model."

"I did understand almost everything".

5) "What is your general evaluation of the programme and workshop?" Participants answered as follows:
"The programme is really useful to me"; The workshop was well planned"; "It added to my knowledge about clinical supervision, it was well planned"; "Active participation was a great opportunity for information sharing"; "The workshop was successful"; "I would like to comment that the workshop of this nature to be done to all supervisors especially "elders"; "To have more workshops on the programme and not only registered nurses from medical and surgical units to attend because students work in different departments"; The sessions were very good, I gained more skills on how to perform clinical supervision and its importance"; "This programme should be shared to all registered nurses, even two times per year".

The participants' overall impression of the workshop was expressed as follows:

"We have enjoyed the discussions, role plays, they taught us who we are, and our responsibilities towards the supervision of student nurses allocated to our units. Without fully knowing who you are, and self-acceptance, change becomes impossible."

"I have identified my weaknesses and I learned how to develop positive attitudes and behaviours towards the clinical supervision of my students."

"We learned how to get rid of fear and maintain self -confidence." One participant summed up the general experiences of the group regarding the implementation of the educational programme by stating that:

"We really enjoyed, we had a lot of fun though educative and motivational; the way the facilitator treated us was very much appreciated. We were treated with respect, dignity and as human beings, thanks."

Based on her observations and her interactions with participants, the facilitator noted that during the workshop registered nurses were quite enthusiastic about sharing experiences on clinical supervision; their interaction and communication among themselves and with student nurses. They showed their interest in and the need for being supported to be able to provide effective clinical supervision to student nurses. They found the workshop was of benefit to them.

Table 2: Educational Implementation Outcomes

\begin{tabular}{|c|c|c|}
\hline Focus areas & Outcomes & Indicators \\
\hline $\begin{array}{l}\text { 1. Programme } \\
\text { implementation }\end{array}$ & $\begin{array}{l}\text { Successful implementation of the programme activi- } \\
\text { ties } \\
\text { Facilitation of the programme content and interven- } \\
\text { tions. } \\
\text { Facilitation of the supportive agents of the pro- } \\
\text { gramme activities. } \\
\text { Make provision of active participation of registered } \\
\text { nurses in programme implementation activities. }\end{array}$ & $\begin{array}{l}\text { Registered nurses from the medical and surgical wards participat- } \\
\text { ed in the programme implementation to support registered nurses } \\
\text { in their provision of clinical supervision of student nurse. Active } \\
\text { participation of registered nurses during the programme imple- } \\
\text { mentation activities. } \\
\text { Active participation, role-plays, group work and penalty feed- } \\
\text { backs that enhance knowledge and skills on how to supervise. }\end{array}$ \\
\hline $\begin{array}{l}3 . \\
\text { outcome }\end{array}$ & $\begin{array}{l}\text { Successfully implementing the programme to support } \\
\text { registered nurses during the clinical supervision of } \\
\text { student nurses. }\end{array}$ & $\begin{array}{l}\text { Identification and provision of knowledge required to registered } \\
\text { nurses/supervisors to be used during clinical supervision. } \\
\text { Identification and mobilization of human and material resources } \\
\text { required during clinical supervision of student nurses. } \\
\text { Registered nurses empowerment to actively take part in clinical } \\
\text { supervision of student nurses. }\end{array}$ \\
\hline Programme limitations & $\begin{array}{l}\text { Need to keep the programme implementation as a } \\
\text { routine for registered nurses during clinical supervi- } \\
\text { sion. }\end{array}$ & $\begin{array}{l}\text { Need for regular follow up to enhance the continuity of the pro- } \\
\text { gramme implementation during clinical practice. }\end{array}$ \\
\hline
\end{tabular}

\section{Post implementation evaluation}

The researcher also conducted focus group discussions with registered nurses and student nurses in the medical and surgical wards, two months after the implementation of the programme. The aim was to assess the long-term effects of the programme activities as might be signified by changes in the way of clinical supervision of student nurses (Metz,., Bowie,. \& Blasé, 2007). Registered nurses indicated that the programme had been effective, and they had started to implement it although motivation and encouragement is always needed to keep the track going. For this purpose an impact evaluation was used. It consisted of the following areas which were considered during the evaluation: programme objectives, evaluation indicators, themes, categories and level of objective achievement. 
1. Tell me what you have learnt from the workshop that is applicable to your daily routine of supervising students in your unit

......................................

$2 . \quad$ Could you please share your experiences on how the implementation of an educational programme you attended address the challenges you are encountering during clinical supervision.



3. Please tell me your experiences regarding the interaction and communication among supervisors and between supervisors and student nurses after the workshop you attended

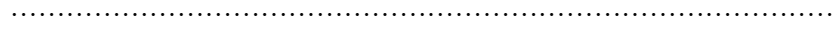

Fig. 2: Post Evaluation Tool for an Educational Programme to Suppor

Registered Nurses during Clinical Supervision

Discussion of findings of the evaluation of the programme implementation

The following was evidence that the programme was implemented in the hospital from the registered nurses, based on the objectives which were planned to be met.

Data from the above findings revealed the following with regards to the successful implementation of the programme.

Programme objective 1: To address the managerial challenges experienced by student nurses and registered nurses during clinical supervision of student nurses in order to support registered nurses during clinical supervision of student nurses

Indicator 1: Minimum managerial and educational challenges experienced during clinical supervision

The programme objective that targeted to address the managerial and educational challenges identified as affecting clinical supervision of student nurses in order to support registered nurses during clinical supervision of student nurses was met. Registered nurses found support from the programme and they were able to manage time and resources better than before; that enabled them to take part and execute clinical supervision of student nurses effectively.

"The programme gave me a starting point to manage my limited time and to be able to have time with my student nurses."

"I did not believe that I will be successful in student supervision with that small number of registered nurses in the unit but when I delegate some tasks to other registered nurses it minimizes my burden and now I am able to care for both my patients and my students as well."

"The programme gave me encouragement to approach my management when I am in need. I was demoralized because I thought that it is just wasting my time but sometimes we need to wait for such a time to get what we want."

"The programme taught me a lesson on how to take care of my resources; I create the feeling of ownership in me."

Programme objective 2: To address the educational challenges experienced by student nurses and registered nurses during clinical supervision of student nurses in order to support registered nurses during clinical supervision of student nurses

Indicator 2: Knowledge and skills acquisition in clinical supervision of student nurses

Registered nurses indicated that their knowledge and skills on clinical supervision were improved. The quotes below support the above statements:

The programme objective was to provide registered nurses with knowledge and skills regarding the concept clinical supervision. This objective was also met. Registered nurses expressed that they were encouraged and motivated to see their role and responsibilities as supervisors. They also indicated that they are confident to provide clinical supervision to student nurses, trying to use the knowledge and skills they gained during the implementation of the programme, but still they emphasized the issue of continuous motivation and encouragement in the form of workshops or group discussion on a regular basis. The above mentioned statements are supported by the following quotes:
"When I am seeing students in the wards they always remind me about the role play which was done on the day of the programme implementation; then I start thinking that let me go and something to my students."

"Since the date I attended the workshop I wanted to do more to the best of my ability to bring the students to where I am now, the programme made me to reflect on how I was cared for by my supervisors when I was a student. I want to do the same; I think they are the best role models."

"Supervision is my task, there is no way I should exempt myself from doing it. The programme bolstered me again; I thought that I am off the road, at least now I know what to do and who to ask if I have queries."

"I did not know that what I should teach my students is what is happening in my ward together with what is in their practical registers. I thought that practical registers are for their lecturers, now I feel proud to be a part of them all."

"The programme adds to my knowledge and it continues to add more. The moment I am supervising students I also learn new things from their registers Oh! It's wonderful."

Programme objective 3: To address non-conducive environment experienced by student nurses and registered nurses during clinical supervision of student nurses in order to support registered nurses during clinical supervision of student nurses

Indicator 3: Improved interaction among supervisors and between supervisors and students

The programme objective was to create a conducive environment for and enhance constructive interpersonal relationships among registered nurses and between registered nurses and student nurses that promote effective clinical supervision. This objective was met.

Registered nurses and student nurses are comfortable with each other when it comes to interaction and communication.

The following quotes support the above findings:

"The programme opened up the door for us to meet with our colleagues at the training institutions to discuss student practical books and supervision."

"Student nurses are our mirror; what they are reflecting is how we treat them; the programme changed my attitude towards them. I want to do my best to show them good examples."

"What I find in this ward is not the same in other wards I have been practicing. The supervisor here is always open and approachable to everyone."

"I am impressed by the programme schedule I found in this ward. I did not experience it before, here people are trying to keep eyes on us and teach us."

"In this ward we are attached to a supervisor every day, at least one knows where to go and ask for help if the need arises."

"Thanks for the programme, I hope that the current routine was born by this programme where we meet with our colleagues from the training institution and that made us to feel as brothers and sisters, now we can do things better."

\section{Conclusion}

The results of the programme evaluation indicate a strong feasibility and successfulness of implementation of the programme activities. The outcomes evaluation indicates that the participants found the programme worthwhile and demonstrated a positive attitude towards the programme, since they were satisfied with the programme and tried to implement the knowledge gained during their routine activities and recommended the decentralization of the programme.

\section{Acknowledgment}

The University of Namibia (UNAM) and Ministry of Health and Social Services, Namibia are gratefully acknowledged for granted me the permission for this kind of professional discourses. 
The hospital management for the Oshakati Intermediate Hospital for creating conducive environment enable me to conduct this study as well as for any kind of support offered to me during this study.
Special acknowledgement is accorded to all registered nurses and nursing students who had taken part in this study, for their contributions and co-operation that made this study possible.

Table 3: Summary of the Programme Evaluation Outcomes

\begin{tabular}{|c|c|c|c|c|}
\hline Programme objective & Evaluation indicator & Themes & Categories & Level of objective achievement \\
\hline $\begin{array}{l}\text { To address the manage- } \\
\text { rial challenges experi- } \\
\text { enced by student nurses } \\
\text { and registered nurses } \\
\text { during clinical supervi- } \\
\text { sion of student nurses in } \\
\text { order to support regis- } \\
\text { tered nurses during } \\
\text { clinical supervision of } \\
\text { student nurses }\end{array}$ & $\begin{array}{l}\text { Minimum managerial } \\
\text { and educational chal- } \\
\text { lenges experienced } \\
\text { during clinical supervi- } \\
\text { sion. }\end{array}$ & $\begin{array}{l}\text { Registered nurses and student } \\
\text { nurses experienced support } \\
\text { from using the programme. }\end{array}$ & $\begin{array}{l}\text { Minimum workload Task } \\
\text { delegated: Improved time } \\
\text { management }\end{array}$ & $\begin{array}{l}\text { Managerial challenges were } \\
\text { addressed and registered nurs- } \\
\text { es supported during clinical } \\
\text { supervision of student nurses. }\end{array}$ \\
\hline $\begin{array}{l}\text { To address the educa- } \\
\text { tional challenges experi- } \\
\text { enced by student nurses } \\
\text { and registered nurses } \\
\text { during clinical supervi- } \\
\text { sion of student nurses in } \\
\text { order to support regis- } \\
\text { tered nurses during } \\
\text { clinical supervision of } \\
\text { student nurses }\end{array}$ & $\begin{array}{l}\text { Knowledge and skills } \\
\text { acquisition in clinical } \\
\text { supervision of student } \\
\text { nurses. }\end{array}$ & $\begin{array}{l}\text { Registered nurses acquired } \\
\text { knowledge and skills regard- } \\
\text { ing supervision from using } \\
\text { the programme. }\end{array}$ & $\begin{array}{l}\text { Information acquisition with } \\
\text { regard to: role modelling, } \\
\text { educational role fulfilment, } \\
\text { on spot teaching, student } \\
\text { follow-up assessment and } \\
\text { evaluation, maintenance of } \\
\text { professional standards. }\end{array}$ & $\begin{array}{l}\text { Knowledgeable, skilled regis- } \\
\text { tered nurses with regards to the } \\
\text { concept clinical supervision; } \\
\text { competent, motivated regis- } \\
\text { tered nurses in the supervision } \\
\text { of students during clinical } \\
\text { practice. }\end{array}$ \\
\hline $\begin{array}{l}\text { To address non- } \\
\text { conducive environment } \\
\text { experienced by student } \\
\text { nurses and registered } \\
\text { nurses during clinical } \\
\text { supervision of student } \\
\text { nurses in order to sup- } \\
\text { port registered nurses } \\
\text { during clinical supervi- } \\
\text { sion of student nurses. }\end{array}$ & $\begin{array}{l}\text { Improved interaction } \\
\text { among supervisors and } \\
\text { between supervisors } \\
\text { and students. }\end{array}$ & $\begin{array}{l}\text { Frequent consultations be- } \\
\text { tween registered nurses as } \\
\text { well as good communication } \\
\text {; behaviour change and good } \\
\text { interaction among supervisors } \\
\text { and between registered nurs- } \\
\text { es and student nurses }\end{array}$ & $\begin{array}{l}\text { Comfortability in interaction } \\
\text { and communication among } \\
\text { registered nurses and between } \\
\text { student nurses and registered } \\
\text { nurses. Frequent consulta- } \\
\text { tions, briefing and infor- } \\
\text { mation sharing between regis- } \\
\text { tered nurses. } \\
\text { Feelings of being supportive, } \\
\text { approachable, willingness and } \\
\text { readiness among registered } \\
\text { nurses. }\end{array}$ & $\begin{array}{l}\text { Committed registered nurses } \\
\text { and supervisors on students } \\
\text { with positive interpersonal } \\
\text { relationships and communica- } \\
\text { tion skills. }\end{array}$ \\
\hline
\end{tabular}

\section{References}

[1] Sharif, F. \& Masoumi, S. (2005). A Qualitative Study of Nursing Students' Experience of clinical Practice: The Cochrane Library.

[2] American Association of College of Nursing, (2011). American Association of College of Nursing faculty shortage fact sheet Retrieved 2.6.2014, from http//www.aacnnche/mediarealtioNrsgShortageFS pdf.

[3] Neshuku, H. (2015) Development of an educational programme to support registered nurses during clinical supervision of student nurses in medical and surgical wards in a training health facility, in the Oshana region, Namibia (Unpublished PhD Dissertation) School of Nursing and Public Health Faculty of Health Sciences University of Namibia, Namibia

[4] Booyens S.W. (2005). Dimension of Nursing Management. Juta \& Co. LTD: Lansdowne S.A.

[5] Royal College of Nursing. (n.d). Clinical supervision in the workplace - Guidance for occupational health nurses Retrieved at http:/www.rcn.org.uk/data/assets/pdffile007/78523/001549.pdf.

[6] Hinchliff, S. (2005). The practitioner as teacher (3rd Ed.). Elsevier: Churchill.

[7] Bezuidenhout, M.C. (2003). Guideline for enhancing clinical supervision. Health SA Gesondheid, 8(4):12-23. http://dx.doi.org/10.4102/hsag.v8i4.142.

[8] Consedine, M. (2004). Clinical values and possibilities. Available on line at http:www.tidal model co uk/clinical-supervision.htm. Retrieved on 9.1.2006.

[9] Driscoll, J. (2000). Practicing Clinical supervision: A Reflective Approach. Bailliere Trinidall: Edinburgh.

[10] Berggren, I. \& Serevinsson, E. (2003). Nurses supervisors' actions in relation to their decision-making styles and ethical approaches to clinical supervision. Journal of Advance Nursing, 41(6), 615-622. http://dx.doi.org/10.1046/j.1365-2648.2003.02573.x.

[11] Cambridge Academic Content Dictionary. (2009). Cambridge: Cambridge University Press.
[12] Kaviana, N.; Sillwell. Y (2000) an evaluation study of clinical preceptorship. Nurse Education Today, 20:3 .218-226 http://dx.doi.org/10.1054/nedt.1999.0386.

[13] Jooste, K. 2003. Promoting a motivational workforce in nursing practice. Health SA Gesondheid, 8(1), 8998. http://dx.doi.org/10.4102/hsag.v8i1.119.

[14] Kilminister, SM., Folly, BC. 2002 Effective supervision in clinica practice settings Literature review medical Education 34:827-840.

[15] Ohrling K Hallberg,. I. (2001) the meaning of preceptorship: Nurse 'lived experience of being preceptor. Journal of Advance Nursing 33:4, 530-540 http://dx.doi.org/10.1046/j.1365-2648.2001.01681.x.

[16] Quinn, F.M. (2001). The Principal and Practice of nurse education. 4th Edition. London: Chapman and Hall.

[17] Mamchur, C., Myrick F 2003 Preceptorship and interpersonal conflict. A multidisciplinary study. Journal of Advance Nursing 43: 2, 388-196 http://dx.doi.org/10.1046/j.1365-2648.2003.02693.x.

[18] Fraser, M.D. \& Cooper, M.A. (2006). Survival guide for midwifery Churchill: Livingstone Elsevier

[19] Metz, A.J.R., Bowie, L. \& Blasé, K. (2007). Seven activities for enhancing the reliability of evidence based practice. Research-tothe Result Brief. Publication No 2007-31. Children Trends. Retrieved on May 192012 from the http: //www. Child trends org/../child trends -2007-10-01 -whyprogeval.

[20] Freeman, C. (2005/2006). Sharing the best Practice across the PTC Clinical supervision guideline for registered nurses. Birkenhead and Wallsey: NHS 